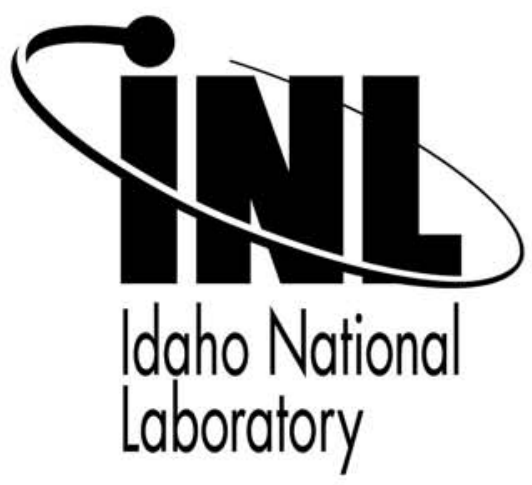

\section{International Heat Transfer Conference}

C. Oh

R. Barner

C. Davis

S. Sherman

\section{August 2006}

This is a preprint of a paper intended for publication in a journal or proceedings. Since changes may not be made before publication, this preprint should not be cited or reproduced without permission of the author. This document was prepared as an account of work sponsored by an agency of the United States Government. Neither the United States Government nor any agency thereof, or any of their employees, makes any warranty, expressed or implied, or assumes any legal liability or responsibility for any third party's use, or the results of such use, of any information, apparatus, product or process disclosed in this report, or represents that its use by such third party would not infringe privately owned rights. The views expressed in this paper are not necessarily those of the United States Government or the sponsoring agency. 


\title{
THERMAL HYDRAULIC ANALYSES FOR COUPLING HIGH TEMPERATURE GAS-COOLED REACTOR TO HYDROGEN PLANT
}

\author{
C. Oh, R. Barner, C. Davis, and S. Sherman \\ Idaho National Laboratory, Idaho Falls, ID. USA
}

\begin{abstract}
The US Department of Energy is investigating the use of high-temperature nuclear reactors to produce hydrogen using either thermochemical cycles or high-temperature electrolysis. Although the hydrogen production processes are in an early stage of development, coupling either of these processes to the high-temperature reactor requires both efficient heat transfer and adequate separation of the facilities to assure that off-normal events in the production facility do not impact the nuclear power plant. An intermediate heat transport loop will be required to separate the operations and safety functions of the nuclear and hydrogen plants. A next generation hightemperature reactor could be envisioned as a single-purpose facility that produces hydrogen or a dual-purpose facility that produces hydrogen and electricity. Early plants, such as the proposed Next Generation Nuclear Plant (NGNP), may be dual-purpose facilities that demonstrate both hydrogen and efficient electrical generation. Later plants could be single-purpose facilities. At this stage of development, both single- and dual-purpose facilities need to be understood.

A number of possible configurations for a system that transfers heat between the nuclear reactor and the hydrogen and/or electrical generation plants were identified. These configurations included both direct and indirect cycles for the production of electricity. Both helium and liquid salts were considered as the working fluid in the intermediate heat transport loop. Methods were developed to perform thermal-hydraulic and cycle-efficiency evaluations of the different configurations and coolants. The thermal-hydraulic evaluations estimated the sizes of various components in the intermediate heat transport loop for the different configurations. The relative sizes of components provide a relative indication of the capital cost associated with the various configurations. Estimates of the overall cycle efficiency of the various configurations were also determined. The evaluations determined which configurations and coolants are the most promising from thermalhydraulic and efficiency points of view.
\end{abstract}

\section{Introduction}

The Department of Energy is investigating the use of high-temperature nuclear reactors to produce hydrogen using either thermochemical cycles or high-temperature electrolysis. Although the hydrogen production processes are in an early stage of development, coupling either of these processes to the high-temperature reactor requires both efficient heat transfer and adequate separation of the facilities to assure that off-normal events in the production facility do not impact the nuclear power plant. An intermediate heat transport loop will be required to separate the operations and safety functions of the nuclear and hydrogen plants. Although an indirect electrical cycle would also require an intermediate loop similar to the loop required for hydrogen production, an electrical cycle would not be anticipated to have the same requirements for significant separation distances that hydrogen plant safety issues would require.

A next generation high-temperature reactor could be envisioned as a single-purpose facility that produces hydrogen or a dual-purpose facility that produces hydrogen and electricity. At the current time, it is anticipated that early plants may be dual-purpose facilities that demonstrate both hydrogen and efficient electrical generation, and that later plants could be single-purpose facilities. At this stage of development, both single- and dual-purpose facilities need to be understood. 
Both helium and liquid salts are being considered as the working fluid in the intermediate heat transport loop. The liquid salts considered in this analysis included LiF-NaF-KF (Flinak) in molar concentrations of $46.5 \%, 11.5 \%$, and $42 \%$, respectively, and $\mathrm{NaBF}_{4}-\mathrm{NaF}$ in molar concentrations of $92 \%$ and $8 \%$. The use of a liquid salt provides the potential for improved heat transfer and reduced pumping powers, but also introduces materials compatibility issues.

This paper describes various intermediate heat transport loop configurations and summarizes the thermal-hydraulic, structural, and efficiency calculations that have been performed to characterize the advantages and issues associated with each configuration. The key issues that are addressed in this report include:

- Configuration options

- System parameters, such as temperature and pressure

- Working fluid options

A number of possible configurations for the high-temperature reactor primary coolant system and the intermediate heat transport loop have been identified. However, due to the page limit, only two configurations are presented in this paper. The ultimate objective of the program is to evaluate the advantages and disadvantages of each of the configurations and working fluids so that a specific design option can be recommended. However, the recommendation of a specific design requires input from a variety of disciplines related to materials, thermal-hydraulics, economics, safety, and plant operability. The purpose of this work is to evaluate the advantages and disadvantages of the configurations and working fluids to provide input to the decision making process.

\section{Design Configurations}

A number of plant configurations were evaluated and results from two configurations are presented. For convenience, the following nomenclature is used relative to the heat exchangers:

- IHX - The first heat exchanger downstream of the NGNP outlet

- PHX - The heat exchanger that connects the intermediate heat transport loop to the hydrogen production plant

- SHX - The heat exchanger that, if present, is located between the IHX and the PHX, and is referred to as the secondary heat exchanger (SHX).

The two plant configurations evaluated are illustrated in Figures 1 and 2. The configurations include direct and indirect electrical cycles as shown in Figures 1 and 2, respectively. The configurations include both serial and parallel heat exchanger options. In the serial option, which is illustrated in Figures 1, the IHX or SHX is located upstream of the power conversion unit (PCU). In the serial option, the heat exchanger removes less than $10 \%$ of the reactor power and directs it towards the hydrogen production plant. With this configuration, the hydrogen production plant receives the highest possible temperature fluid while the PCU receives a lower temperature fluid. This configuration is relatively simple and is especially suitable for the demonstration of hydrogen production. However, the overall efficiency of the electrical production process will be reduced. In the parallel heat exchanger option, which is illustrated in Figures 2, the hottest fluid is divided, with most going towards the PCU and the remainder going towards the hydrogen production plant. This configuration is more complicated, but results in a higher overall efficiency because both the electrical and hydrogen production plants see the maximum possible temperature. With these options, a small compressor or blower is required to compensate for the pressure loss across the IHX or SHX and allow the fluid streams to mix downstream of the recuperator. The final option uses a SHX as shown in Figure 2. This option utilizes a third or tertiary coolant loop that provides 
additional separation between the nuclear and hydrogen plants, which should increase the safety of both plants and may make the nuclear plant easier to license. However, this option requires more capital investment and lowers the overall efficiency of the plant.

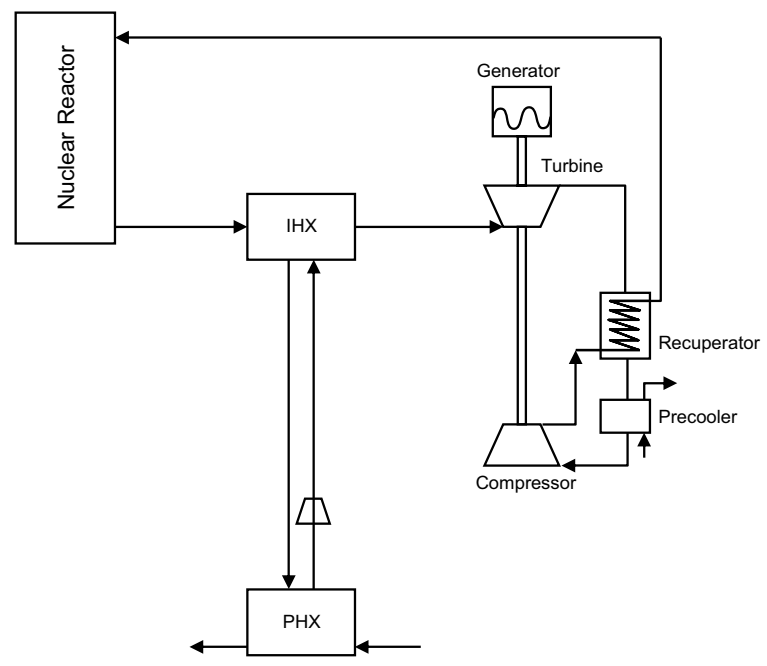

Figure 1. Configuration 1 (direct electrical cycle and a serial IHX).

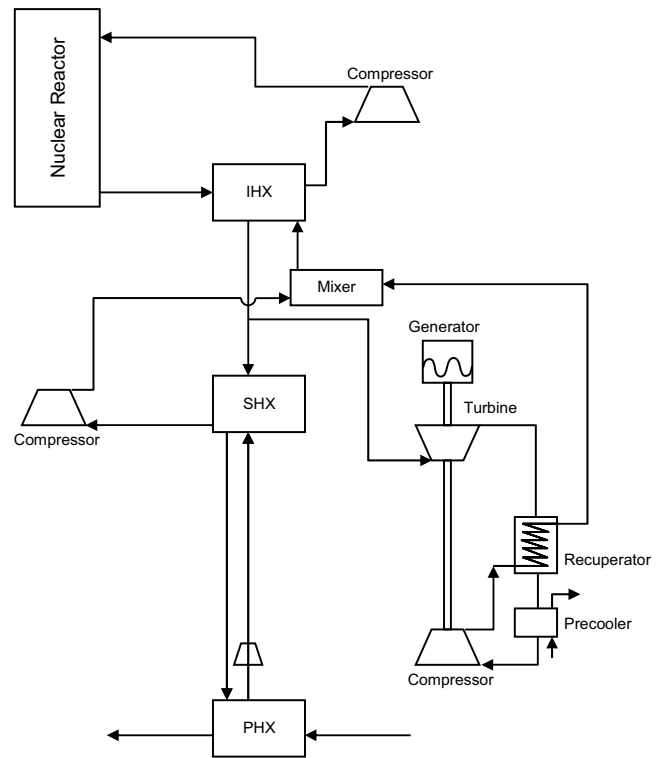

Figure 2. Configuration 6 (indirect electrical cycle and a parallel SHX).

The Independent Technology Review Group (2004) recommended the use of an indirect cycle for the NGNP because it was judged to be more practical for operation and to involve less developmental risk than a direct cycle. 


\section{Methods}

\subsection{Component Sizing}

The nominal temperature drop between the outlet of the NGNP and the maximum temperature delivered to the hydrogen production plant is assumed to be $50{ }^{\circ} \mathrm{C}$. This temperature drop imposes requirements on the effectiveness of the heat exchangers that connect the NGNP and the production plant and the amount of heat loss than can be tolerated in the intermediate loop. Although the total temperature drop between the NGNP and the production plant is fixed by assumption, the distribution of the temperature drop between the heat exchangers and heat loss can be varied. For example, if the heat loss can be reduced, the temperature drops across the heat exchangers can be increased and smaller heat exchangers can be used. After accounting for heat loss, the remaining temperature drop between the outlet of the NGNP and the maximum temperature delivered to the hydrogen production plant is divided evenly between the IHX, PHX, and, if present, the SHX.

As mentioned previously, the temperature drop between the NGNP and the production plant imposes requirements on the heat exchangers. The effectiveness of a heat exchanger, $\varepsilon$, (Kreith 1964) can be calculated as

$\varepsilon=\frac{\left(\dot{\mathrm{m}} \mathrm{c}_{\mathrm{p}}\right)_{\mathrm{h}}\left(\mathrm{T}_{\mathrm{hin}}-\mathrm{T}_{\mathrm{hout}}\right)}{\left(\dot{\mathrm{mc}} \mathrm{c}_{\mathrm{p}}\right)_{\min }\left(\mathrm{T}_{\mathrm{hin}}-\mathrm{T}_{\mathrm{cin}}\right)}$

where $\dot{m}$ is the mass flow rate, $c_{p}$ is the specific heat capacity at constant pressure and is assumed constant, and $\mathrm{T}$ is the temperature. The subscripts $\mathrm{h}$ and $\mathrm{c}$ refer to the hot and cold sides of the heat exchanger, the subscripts in and out refer to the inlet and outlet ends of the heat exchanger, and the subscript min refers to the minimum value for the hot and cold sides.

The heat exchangers are assumed to be in counterflow, which requires less surface area than is required for parallel flow (Kreith 1964). Counterflow heat exchangers are therefore smaller, and presumably cheaper, than corresponding heat exchangers in parallel flow. If the values of $\dot{m}_{\mathrm{p}}$ are the same for the hot and cold streams, the effectiveness depends only on the inlet and outlet temperatures.

Estimates are also made to size the heat exchangers. The required heat transfer area, $A_{h t}$, can be calculated from equations given by Krieth (1964)

$$
\mathrm{A}_{\mathrm{ht}}=\frac{\varepsilon\left(\dot{\mathrm{mc}}_{\mathrm{p}}\right)_{\min }\left(\mathrm{T}_{\mathrm{hin}}-\mathrm{T}_{\mathrm{cin}}\right)}{\mathrm{U} \Delta \mathrm{T}}
$$

where $\mathrm{U}$ is the overall heat transfer coefficient and $\Delta \mathrm{T}$ is the log-mean temperature difference, which is calculated as

$$
\Delta \mathrm{T}=\frac{\Delta \mathrm{T}_{\mathrm{a}}-\Delta \mathrm{T}_{\mathrm{b}}}{\ln \left(\Delta \mathrm{T}_{\mathrm{a}} / \Delta \mathrm{T}_{\mathrm{b}}\right)}
$$

where $\Delta \mathrm{T}_{\mathrm{a}}$ is the temperature difference between the hot and cold fluid streams at one end of the heat exchanger and $\Delta \mathrm{T}_{\mathrm{b}}$ is the temperature difference at the other end. The overall heat transfer coefficient is calculated from the heat transfer coefficients on both sides of the exchanger and the thermal conductivity and thickness of the metal. The heat transfer coefficients and the thermal conductivity are assumed constant over the length of the heat exchanger. For turbulent flow, the 
heat transfer coefficients are calculated using the Dittus-Boelter correlation, with a leading coefficient of 0.021 for gases and 0.023 for liquids (INEEL 2003a). For laminar flow, the heat transfer coefficients are calculated from the exact solution for fully developed flow with constant heating rate (Kayes and Crawford 1980). The thermal conductivity of the metal is calculated assuming Alloy 800, and varies between 18 and $26 \mathrm{~W} / \mathrm{m}-\mathrm{K}$ over the temperature range of interest.

The pressure drop across a component is calculated from either the Blausius equation (Bird et al. 1960 ) or the more accurate Zigrang-Sylvester correlation (INEEL 2003b) for turbulent flow and the exact solution for fully developed laminar flow in a tube (Bird et al. 1960).

The front face of the IHX is assumed to be square. Iterations are performed to determine the width of the IHX. First, a diameter of the semicircular flow channel is assumed. The plate thickness and pitch between channels are then calculated from the geometry. A width of the IHX is then assumed. The flow areas of the hot and cold streams are then calculated from the width and geometries of the channels and plates. The mass flow rates for both streams are calculated from an energy balance and the assumed inlet and outlet temperatures. The overall heat transfer coefficient and effectiveness are then calculated. The required heat transfer area is then calculated from Equation (2). The length of the heat exchanger is then calculated from heat transfer area and the wetted perimeter of the channels, which allows the calculation of the pressure drop. The heat exchanger width is then varied until the desired pressure drop is obtained.

A similar method is used for the tube-in-shell PHX. First, the tube inner diameter is assumed. The tube thickness is then calculated from ratios determined in the stress analysis. The pitch-to-outerdiameter ratio of the tubes is set to 1.3, a typical value for tube bundles. The tube bundle is assumed to have a triangular pitch. Details on the heat transfer coefficients and fluid temperature distribution on the process side of the PHX are not yet available. Consequently, the heat transfer coefficient on the process side is assumed to be $2000 \mathrm{~W} / \mathrm{m}^{2}-\mathrm{K}$, which is a representative value for the conditions being considered. The inlet and outlet fluid temperatures on the process side are also assumed. The inner diameter of the shell is then varied until the desired pressure drop is obtained.

The inner diameters of the hot and cold leg pipes in the heat transport loop are sized to produce a given pressure drop. The thickness of the piping is based on the results of the stress analysis. The heat loss is calculated using an overall heat transfer coefficient, which accounts for the thermal resistance of the heat transfer coefficient at the inner and outer surfaces, the pipe metal, and the insulation (Bird et al. 1960). Specifically,

$$
\mathrm{U}_{0}=\frac{1}{\mathrm{r}_{0}\left(\frac{1}{\mathrm{r}_{0} \mathrm{~h}_{0}}+\frac{\ln \left(\mathrm{r}_{1} / \mathrm{r}_{0}\right)}{\mathrm{k}_{1}}+\frac{\ln \left(\mathrm{r}_{2} / \mathrm{r}_{1}\right)}{\mathrm{k}_{2}}+\frac{1}{\mathrm{r}_{2} \mathrm{~h}_{2}}\right)},
$$

where $\mathrm{U}_{0}$ is the overall heat transfer coefficient based on the inner surface area of the pipe, $\mathrm{k}_{1}$ and $\mathrm{k}_{2}$ are the thermal conductivities of the pipe metal and insulation, respectively, and $r_{0}, r_{1}$, and $r_{2}$ are the radii of the inner surface of the metal, the outer surface of the metal, and the other surface of the insulation, respectively. The heat transfer coefficient at the inner surface, $\mathrm{h}_{0}$, is calculated using the Dittus-Boelter correlation (INEEL 2003a) as described previously. The heat transfer coefficient at the outer surface, $\mathrm{h}_{2}$, accounts for natural convection and radiation. The convective contribution is calculated using the Churchill-Chu correlation for natural convection from a horizontal cylinder (Holman 1986). The radiation term is calculated assuming that the pipe is in a large enclosure (Homan 1986), such as in a buried conduit. The thermal conductivity of the metal is based on Alloy 800. The thermal conductivity of the insulation is assumed to be $0.1 \mathrm{~W} / \mathrm{m}-\mathrm{K}$, which is a representative value for glasswool. The thickness of the insulation is varied to obtain the desired heat loss. In case an alternate insulation material is eventually selected, the required thickness can 
be approximated by the thickness value reported here multiplied by the ratio of the actual thermal conductivity to the assumed thermal conductivity.

Estimates of the pumping power, $\mathrm{Q}_{\mathrm{p}}$, are approximated using

$\mathrm{Q}_{\mathrm{p}}=\frac{\dot{\mathrm{m}} \Delta \mathrm{P}}{\rho}$,

where $\dot{\mathrm{m}}$ is the mass flow rate, $\Delta \mathrm{P}$ is the pressure drop, and $\rho$ is the fluid density (Glasstone and Sesonske 1967). The fluid density is based on the temperature at the inlet to the reactor for the hot stream of the IHX and based on the temperature of the cold stream entering the IHX or the SHX for the intermediate and tertiary loops.

\subsection{Efficiency Evaluation}

The efficiency of each proposed configuration was estimated using HYSYS (Aspen Technology 2005), a process optimization code used in the chemical and oil industries. Input models were developed for each of the configurations illustrated in Figures 1 and 2.

The PCU cycle efficiency (Oh, 2005), $\eta_{\mathrm{PCU}}$, used in this study is defined as:

$\eta_{\mathrm{PCU}}=\frac{\text { Electric power output }}{\text { Reactor thermal power }-\mathrm{H}_{2} \text { process power }}=\frac{\Sigma \mathrm{W}_{\mathrm{T}}-\Sigma \mathrm{W}_{\mathrm{C}}-\mathrm{W}_{\mathrm{S}}-\Sigma \mathrm{W}_{\mathrm{CIR}}}{\mathrm{Q}_{\mathrm{th}}-\mathrm{Q}_{\mathrm{H} 2}}$,

where $\Sigma \mathrm{W}_{\mathrm{T}}$ is the total turbine workload, $\Sigma \mathrm{W}_{\mathrm{C}}$ is the total compressor workload, $\mathrm{W}_{\mathrm{S}}$ is the plant stationary load, $\Sigma \mathrm{W}_{\mathrm{CIR}}$ is the circulator workload in the primary, intermediate, and, if present, tertiary loops, $\mathrm{Q}_{\text {th }}$ is the reactor thermal power, and $\mathrm{Q}_{\mathrm{H} 2}$ is the power supplied through the $\mathrm{PHX}$ to the hydrogen generating plant. For the efficiency calculations, we report the overall cycle efficiency, which is defined as

$\eta_{\text {overall }}=\frac{\Sigma \mathrm{W}_{\mathrm{T}}-\Sigma \mathrm{W}_{\mathrm{C}}-\mathrm{W}_{\mathrm{S}}-\Sigma \mathrm{W}_{\mathrm{CIR}}+0.5 * \mathrm{Q}_{\mathrm{H} 2}}{\mathrm{Q}_{\text {th }}}$,

where the efficiency of the hydrogen generation process was assumed to be a target of $50 \%$. The plant stationary load was neglected in the current analysis.

The polytropic efficiency, rather than the isentropic efficiency, is used for representing the efficiency of the turbomachinery. The equations for the expansion and compression processes in a perfect gas are taken from Saravanamuttoo et al. (1996). For an expansion, the efficiency is calculated from

$\frac{T_{0, e x}}{T_{0, i n}}=\left(\frac{P_{0, e x}}{P_{0, i n}}\right)^{\left(\frac{R}{C_{P}} \eta_{p, e}\right)}$,

where $R$ is the gas constant, $C_{p}$ is the specific heat, $\eta_{p, e}$ is the turbine polytropic efficiency, $T_{0}$ is the stagnation temperature, and $\mathrm{P}_{0}$ is the stagnation pressure. Subscripts $e x$ and in refer to exit gas and inlet gas, respectively. For a compression, the efficiency is calculated from

$\left.\frac{T_{0, e x}}{T_{0, \text { in }}}=\left(\frac{P_{0, e x}}{P_{0, \text { in }}}\right)^{\left(\frac{R}{C_{P}} \frac{1}{\eta_{p, c}}\right.}\right)$. 
HYSYS was used to develop an input model for each configuration and working fluid and to optimize the cycle efficiency. HYSYS uses the Peng-Robinson (1976) equation of state to determine the properties of the working fluids. However, HYSYS does not have thermal properties for molten salts. Therefore, the physical and thermal properties of Flinak and $\mathrm{NaBF}_{4}-\mathrm{NaF}$ were input as hypothetical components in tabular form.

The efficiencies of the turbine and compressors were assumed to be $92 \%$ and $90 \%$, respectively. Figures 1 and 2 show a single shaft connecting one turbine and one compressor. However, two compressors, a high-pressure compressor (HPC) and a low-pressure compressor (LPC), were used for better cycle efficiency. The pressure ratio, which is defined as the outlet pressure from the HPC divided by the inlet pressure to the LPC, was varied to optimize the overall cycle efficiency. Each compressor was assumed to provide half of the overall pumping power. Cooling was applied between compressors to reduce the power consumed by the HPC. Cooler components were used to simulate the heat loss and differential pressure along the hot and cold legs of the intermediate heat transport loop.

\section{Results}

The HYSYS (Aspen Technology 2005a) computer code was used to calculate the overall cycle efficiency for the configurations illustrated in Figures 1 and 2.

The overall efficiency of each configuration was evaluated using the HYSYS model. Figure 3 shows a snapshot of the HYSYS simulation of Configuration 1. Table 1 summarizes the important parameters in the simulation. The overall cycle efficiency calculated from Equation (7) was 50.6\%.

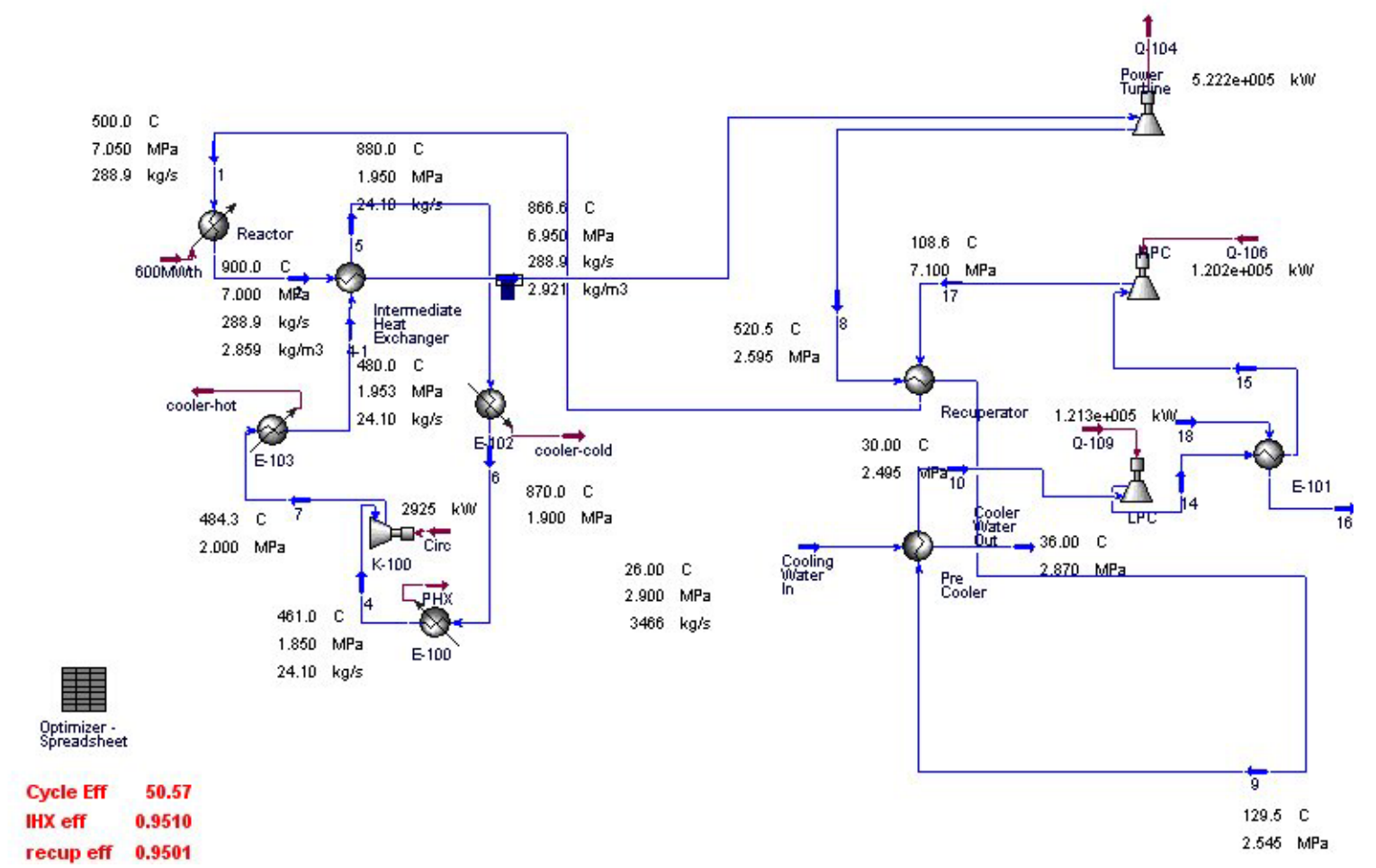

Figure 3. Snapshot of the HYSYS model of Configuration 1.

Table 1. PCU parameters for Configuration 1.

\begin{tabular}{|c|c|}
\hline & HYSYS Results \\
\hline Reactor power & $600 \mathrm{MW}$-thermal \\
\hline Reactor inlet & $500^{\circ} \mathrm{C}$ \\
\hline
\end{tabular}




\begin{tabular}{|c|c|}
\hline & $7.05 \mathrm{MPa}$ \\
\hline \multirow{2}{*}{ Reactor outlet } & $900^{\circ} \mathrm{C}$ \\
\cline { 2 - 2 } & $7.0 \mathrm{MPa}$ \\
\hline $\begin{array}{c}\text { Helium mass } \\
\text { flow to PCU }\end{array}$ & $288.9 \mathrm{~kg} / \mathrm{s}$ \\
\hline Turbine inlet & $866.6^{\circ} \mathrm{C}$ \\
\cline { 2 - 2 } & $6.95 \mathrm{MPa}$ \\
\hline HPC outlet & $108.6^{\circ} \mathrm{C}$ \\
\cline { 2 - 2 } $\begin{array}{c}\text { Flow rate of } \\
\text { intermediate loop }\end{array}$ & $7.1 \mathrm{MPa}$ \\
\hline Pressure ratio & $24.1 \mathrm{~kg} / \mathrm{s}$ \\
\hline $\begin{array}{c}\text { Overall cycle } \\
\text { efficiency }\end{array}$ & 2.85 \\
\hline
\end{tabular}

Calculations were performed to investigate the sensitivity of the overall efficiency to various parameters, including reactor outlet temperature, mass flow rate to the PCU, and pressure.

The sensitivity of the calculated results to variations in reactor outlet temperature between 900 and $1000{ }^{\circ} \mathrm{C}$ was determined. In order to maintain the mass flow rate through the core, the reactor inlet temperature was also raised. The results are summarized below for Configuration 1.

Table 2. Sensitivity of overall efficiency to reactor outlet temperature.

\begin{tabular}{|c|c|c|c|}
\hline & $\mathbf{9 0 0}^{\circ} \mathbf{C}$ & $\mathbf{9 5 0}^{\circ} \mathbf{C}$ & $\mathbf{1 0 0 0}^{\circ} \mathbf{C}$ \\
\hline \multirow{2}{*}{ Reactor power } & $\begin{array}{c}600 \mathrm{MW} \\
\text { thermal }\end{array}$ & $\begin{array}{c}600 \mathrm{MW} \\
\text { thermal }\end{array}$ & $\begin{array}{c}600 \mathrm{MW} \\
\text { thermal }\end{array}$ \\
\hline \multirow{2}{*}{$\begin{array}{c}\text { Reactor inlet } / \\
\text { outlet temperature }\end{array}$} & $\begin{array}{c}500^{\circ} \mathrm{C} / \\
900{ }^{\circ} \mathrm{C}\end{array}$ & $\begin{array}{c}550^{\circ} \mathrm{C} / \\
950^{\circ} \mathrm{C}\end{array}$ & $\begin{array}{c}600{ }^{\circ} \mathrm{C} / \\
1000\end{array}$ \\
\hline \multirow{2}{*}{ Turbine inlet } & $866.6^{\circ} \mathrm{C}$ & $916.6^{\circ} \mathrm{C}$ & $966.6^{\circ} \mathrm{C}$ \\
\cline { 2 - 4 } & $288.9 \mathrm{~kg} / \mathrm{s}$ & $288.9 \mathrm{~kg} / \mathrm{s}$ & $288.9 \mathrm{~kg} / \mathrm{s}$ \\
\hline \multirow{2}{*}{ HPC outlet } & $108.6^{\circ} \mathrm{C}$ & $103.9{ }^{\circ} \mathrm{C}$ & $99.5{ }^{\circ} \mathrm{C}$ \\
\cline { 2 - 4 } & $7.1 \mathrm{MPa}$ & $7.1 \mathrm{MPa}$ & $7.1 \mathrm{MPa}$ \\
\hline Flow rate to IHX & $24.1 \mathrm{~kg} / \mathrm{s} \mathrm{He}$ & $24.1 \mathrm{~kg} / \mathrm{s} \mathrm{He}$ & $24.1 \mathrm{~kg} / \mathrm{s} \mathrm{He}$ \\
\hline Pressure ratio & 2.85 & 2.71 & 2.54 \\
\hline Cycle efficiency & $50.6 \%$ & $52.3 \%$ & $53.9 \%$ \\
\hline
\end{tabular}

The system pressure also affects the cycle efficiency. Using Configuration 6, the compressor outlet pressure was varied from 2 to $7 \mathrm{MPa}$ while the pressure ratio was adjusted to maximize cycle efficiency. Lower system pressure will reduce material stresses, reducing the size of the components, while higher pressure increases overall cycle efficiency. Therefore, a trade-off study between component size and cycle efficiency needs to be performed to determine the optimal design. The effects of system pressure on various parameters are summarized in Table 3 . The effects on overall efficiency are presented in Figure 4.

Table 3. Sensitivity of overall efficiency to pressure.

\begin{tabular}{|c|c|c|c|}
\hline & $\mathbf{2} \mathbf{M P a}$ & $\mathbf{3} \mathbf{M P a}$ & $\mathbf{4} \mathbf{M P a}$ \\
\hline Reactor power & $\begin{array}{c}600 \mathrm{MW} \\
\text { thermal }\end{array}$ & $\begin{array}{c}600 \mathrm{MW} \\
\text { thermal }\end{array}$ & $\begin{array}{c}600 \mathrm{MW} \\
\text { thermal }\end{array}$ \\
\hline
\end{tabular}




\begin{tabular}{|c|c|c|c|}
\hline $\begin{array}{c}\text { Reactor inlet / } \\
\text { outlet temperature }\end{array}$ & $\begin{array}{c}500{ }^{\circ} \mathrm{C} / \\
900{ }^{\circ} \mathrm{C}\end{array}$ & $\begin{array}{c}500{ }^{\circ} \mathrm{C} / \\
900{ }^{\circ} \mathrm{C}\end{array}$ & $\begin{array}{c}500{ }^{\circ} \mathrm{C} / \\
900{ }^{\circ} \mathrm{C}\end{array}$ \\
\hline \multirow{2}{*}{ Turbine inlet } & $866.6^{\circ} \mathrm{C}$ & $886.6^{\circ} \mathrm{C}$ & $866.6^{\circ} \mathrm{C}$ \\
\cline { 2 - 4 } & $259.9 \mathrm{~kg} / \mathrm{s}$ & $259.9 \mathrm{~kg} / \mathrm{s}$ & $259.9 \mathrm{~kg} / \mathrm{s}$ \\
\hline \multirow{2}{*}{$\mathrm{HPC}$ outlet } & $137.5^{\circ} \mathrm{C}$ & $132.9^{\circ} \mathrm{C}$ & $129.7{ }^{\circ} \mathrm{C}$ \\
\cline { 2 - 4 } & $2 \mathrm{MPa}$ & $3 \mathrm{MPa}$ & $4 \mathrm{MPa}$ \\
\hline Flow rate to SHX & $27.5 \mathrm{~kg} / \mathrm{s} \mathrm{He}$ & $27.5 \mathrm{~kg} / \mathrm{s} \mathrm{He}$ & $27.5 \mathrm{~kg} / \mathrm{s} \mathrm{He}$ \\
\hline Pressure ratio & 3.94 & 3.61 & 3.47 \\
\hline Cycle efficiency & $41.4 \%$ & $45.4 \%$ & $47.3 \%$ \\
\hline & & & $7 \mathbf{M P a}$ \\
\hline & $\mathbf{5 ~ M P a}$ & $\mathbf{6 ~ M P a}$ & $600 \mathrm{MW}$ \\
\hline \multirow{2}{*}{ Reactor power } & $600 \mathrm{MW}$ & $600 \mathrm{MW}$ & thermal \\
\hline Reactor inlet / & $500^{\circ} \mathrm{C} /$ & $500{ }^{\circ} \mathrm{C} /$ & $500{ }^{\circ} \mathrm{C} /$ \\
outlet temperature & $900{ }^{\circ} \mathrm{C}$ & $900{ }^{\circ} \mathrm{C}$ & $900{ }^{\circ} \mathrm{C}$ \\
\hline Turbine inlet & $866.6^{\circ} \mathrm{C}$ & $886.6^{\circ} \mathrm{C}$ & $866.6^{\circ} \mathrm{C}$ \\
\hline & $259.9 \mathrm{~kg} / \mathrm{s}$ & $259.9 \mathrm{~kg} / \mathrm{s}$ & $259.9 \mathrm{~kg} / \mathrm{s}$ \\
\hline HPC outlet & $128.6^{\circ} \mathrm{C}$ & $126.7{ }^{\circ} \mathrm{C}$ & $126.3{ }^{\circ} \mathrm{C}$ \\
\hline & $5 \mathrm{MPa}$ & $6 \mathrm{MPa}$ & $7 \mathrm{MPa}$ \\
\hline Flow rate to SHX & $27.5 \mathrm{~kg} / \mathrm{s} \mathrm{He}$ & $27.5 \mathrm{~kg} / \mathrm{s} \mathrm{He}$ & $27.5 \mathrm{~kg} / \mathrm{s} \mathrm{He}$ \\
\hline Pressure ratio & 3.39 & 3.33 & 3.30 \\
\hline Cycle efficiency & $48.4 \%$ & $49.1 \%$ & $49.6 \%$ \\
\hline
\end{tabular}

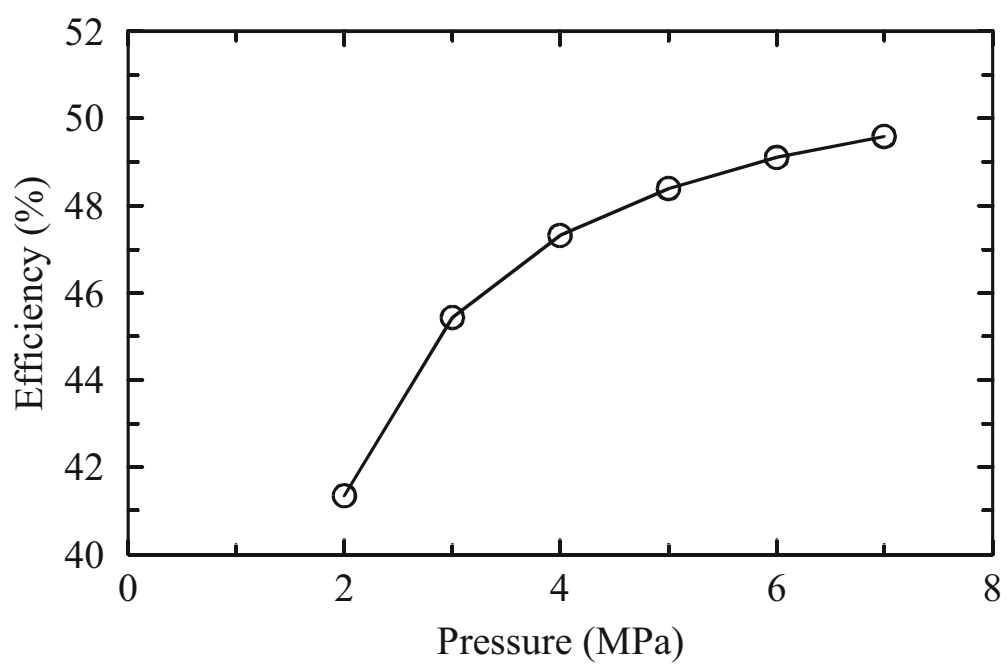

Figure 4. Sensitivity of overall efficiency to pressure.

Calculations were also performed to investigate the sensitivity of the calculated results to the working fluid. The working fluid affects the cycle operating condition, the efficiency, and the size of the plant components, which will be a major factor for the system cost. The previously reported results utilized helium as the working fluid. Sensitivity calculations were performed using the liquid salts Flinak and $\mathrm{NaBF}_{4}-\mathrm{NaF}$.

Using Configuration 1, the helium in the intermediate heat transport loop was replaced with Flinak in the HYSYS model. The results are compared in Table 4. The pumping power in the intermediate heat transport loop was significantly smaller with Flinak as the working fluid. 
However, the difference in cycle efficiency was relatively small $(0.2 \%)$ because the pumping power was small compared to the reactor power even with helium as the working fluid.

Table 4. The effect of working fluid on the overall efficiency for Configuration 1.

\begin{tabular}{|c|c|c|}
\hline & Helium & Flinak \\
\hline Reactor power & $600 \mathrm{MW}$-thermal & $600 \mathrm{MW}$-thermal \\
\hline Configuration & Direct and serial IHX & Direct and serial IHX \\
\hline \multirow{2}{*}{ Reactor inlet } & $500{ }^{\circ} \mathrm{C}$ & $500{ }^{\circ} \mathrm{C}$ \\
\cline { 2 - 3 } & $7.05 \mathrm{MPa}$ & $7.05 \mathrm{MPa}$ \\
\hline Reactor outlet & $900{ }^{\circ} \mathrm{C}$ & $900{ }^{\circ} \mathrm{C}$ \\
\cline { 2 - 3 } & $7.0 \mathrm{MPa}$ & $7.0 \mathrm{MPa}$ \\
\hline $\begin{array}{c}\text { Helium mass } \\
\text { flow to PCU }\end{array}$ & $288.9 \mathrm{~kg} / \mathrm{s}$ & $288.9 \mathrm{~kg} / \mathrm{s}$ \\
\hline Turbine inlet & $866.6^{\circ} \mathrm{C}$ & $866.6^{\circ} \mathrm{C}$ \\
\cline { 2 - 3 } & $6.95 \mathrm{MPa}$ & $6.95 \mathrm{MPa}$ \\
\hline HPC outlet & $108.6{ }^{\circ} \mathrm{C}$ & $108.6{ }^{\circ} \mathrm{C}$ \\
\cline { 2 - 3 } & $7.1 \mathrm{MPa}$ & $7.1 \mathrm{MPa}$ \\
\hline $\begin{array}{c}\text { Flow rate of } \\
\text { intermediate loop }\end{array}$ & $24.1 \mathrm{~kg} / \mathrm{s} \mathrm{He}$ & $133 \mathrm{~kg} / \mathrm{s} \mathrm{Flinak}$ \\
\hline Pressure ratio & 2.85 & 2.85 \\
\hline Pump power & $3.2 \mathrm{MW}$ & $47.9 \mathrm{~kW}$ \\
\hline Cycle efficiency & $50.6 \%$ & $50.8 \%$ \\
\hline
\end{tabular}

\section{Conclusions}

The parametric studies provide an overview of the effects of configuration, operating pressure, temperature, mass flow, and coolant on the efficiency of dual-purpose plants that generate both hydrogen and electricity. The effects of these parameters on the overall efficiency of the plant are summarized below.

- The use of an indirect cycle causes the overall efficiency of the plant to decrease by $1.1 \%$ compared to a direct cycle based on the temperature drop assumptions used for this analysis.

- The use of a liquid salt as the working fluid in the intermediate heat transport loop of the dual-purpose facility analyzed here causes the overall efficiency to increase by $0.2-0.6 \%$ compared to low-pressure helium because of reduced pumping power.

- The use of a heat exchanger that is arranged in parallel with the PCU causes the overall efficiency to increase by $0.1-0.3 \%$ compared to the use a heat exchanger that is arranged in series.

- The variations in overall efficiency were generally small between configurations, except for Configuration 7, where the efficiency was significantly less because of the relatively low operating pressure for this configuration.

- An increase in the reactor outlet temperature of $100{ }^{\circ} \mathrm{C}$ caused the overall efficiency to increase by $3.3 \%$.

- An $11 \%$ decrease in the flow rate through the turbine caused the overall efficiency to decrease by $1.5 \%$. 


\section{Acknowledgment}

This work was supported through the Department of Energy's Power Conversion Program under DOE Idaho Operations Office Contract DE-AC07-99ID13727.

\section{References}

Aspen Technology, 2005, “HYSYS Process Version 2.2.2,” www.aspentech.com.

Bird, R. B., W. E. Stewart, and E. N. Lightfoot, 1960, Transport Phenomena, John Wiley \& Sons, Inc., New York.

Krieth, F., 1964, Principles of Heat Transfer, International Textbook Company, Scranton.

Glasstone, S. and A. Sesonske, 1967, Nuclear Reactor Engineering, Van Nostrand Reinhold Co., New York.

Holman, J. P., 1986, Heat Transfer, Sixth Edition, McGraw-Hill Book Company, New York.

Independent Technology Review Group, 2004, Design Features and Technology Uncertainties for the Next Generation Nuclear Plant, INEEL/EXT-04-01816, June 2004.

INEEL, 2003a, RELAP5-3D Code Manual Volume 4: Models and Correlations, INEEL-98-00834, Revision 2.2, October 2003.

INEEL, 2003b, RELAP5-3D Code Manual Volume 1: Code Structure, System Models and Solution Methods, INEEL-98-00834, Revision 2.2, October 2003.

Kayes, W. M. and M. E. Crawford, 1980, Convective Heat and Mass Transfer, Second Edition, McGraw-Hill Book Company, New York.

Oh, C. and R. Moore, 2005, "Brayton Cycle for High Temperature Gas-Cooled Reactors," Nuclear Technology, Vol. 149, pp. 324-336.

Peng, D.Y. and Robinson, D.B., 1976, "A Two Constant Equation of State," I.E.C. Fundamentals, 15, pp. 59-64.

Saravanamuttoo, H. et al., 1996, Gas Turbine Theory, Fifth Edition, Prentice Hall. 